\title{
EL CONTROL INTERNO EN LA EMPRESA
}

\section{INTERNAL CONTROL IN THE ENTERPRISE}

Iván Frías Lizama

Socio de Auditoría de EY (antes Ernst \& Young), Arequipa, Perú

\section{Resumen:}

En el presente trabajo se analizan los diversos aspectos del control interno en la empresa, tomando como criterios base los componentes del informe COSO. Estos componentes son: entorno del control, evaluación de riesgos, actividades de control, información y comunicación, y monitoreo. Cada uno de estos componentes es revisado y detallado críticamente, con la finalidad de bridar información relevante y aplicable sobre el tema. Se presentan asimismo, los 17 principios del control interno y un modelo sugerido de los criterios a evaluar del entorno de control.

Palabras Clave: Control interno, empresa, entorno de control, evaluación de riesgos, actividades de control, información y comunicación, monitoreo.

\begin{abstract}
:
In the present work we analyze several aspects of internal control in the enterprise, taking as basic criteria the components of the COSO report. These components are control environment, evaluation of risks, control activities, information and communication, and monitoring. Each one of these components is reviewed and critical detailed, with the aim to give relevant and applied information about this topic. Moreover, there are presented 17 principles of internal control and a suggested model with the criteria to value control environment.
\end{abstract}


Key words: Internal control, enterprise, control environment, evaluation of risks, control activities, information and communication, monitoring.

\section{Introducción}

El entorno en el cual las compañías conducen sus negocios está cambiando dramáticamente. Los factores económicos, los avances en la tecnología y la creciente competencia global son sólo unos pocos ejemplos de estos cambios. Con cada nuevo acontecimiento, la gerencia se enfrenta con retos mayores para controlar costos, administrar la liquidez y lograr una ventaja competitiva.

Estos retos han intensificado la preocupación de la gerencia y de los directores respecto a su capacidad para evaluar el desempeño operativo (Méndez, 2011).

En el mundo existen normas que rigen el control interno para empresas, en EE.UU. existe la Ley Sarbanes-Oxley Act of 2002 o SOX 404, para empresas que cotizan en la SEC (Securities and Exchange Commission, 2002), sin embargo existe un marco de referencia que rige las normas y pautas para empresas en el mundo y es el marco integrado de control interno emitido por el Committee of Sponsoring Organizations of the Treadway Commission (COSO, modificado en 2013), que sustituye al anterior COSO 1992. El nuevo marco es el resultado de una vasta aportación de distintos interesados del ambiente de negocios, firmas de auditoría, participantes en los merca- dos financieros y estudiosos del tema. La actualización que dio como resultado el COSO 2013 se basó en la revisión de los objetivos de control interno, para incorporar los cambios en el ambiente de negocios y operativo, articular y formalizar los principios asociados a los componentes de control interno (ya existentes implícitamente) y ampliar la aplicación del sistema de control interno (Committee of Sponsoring Organizations of the Treadway Commission, 1992).

Ahora bien, veamos, como las empresas en el entorno en que se encuentran, pueden aplicar los componentes de control interno que dicta COSO, revisaremos aquí, la forma de implementarlo y las ventajas y beneficios que ello implica.

\section{La importancia del Control Interno}

Los controles internos son fundamentales para lograr un registro exacto de las transacciones y la preparación de reportes financieros confiables. Muchas actividades de negocios involucran diariamente un alto volumen de transacciones y numerosos juicios. Sin controles adecuados que aseguren el registro apropiado de las transacciones, la información financiera resultante puede no ser confiable y debilitar la habilidad de la gerencia para tomar decisiones, así como su credibilidad ante 
los accionistas, las autoridades reguladoras y el público.

Una estructura de control interno eficaz (conocida también como sistema de control interno o, simplemente, como control interno) es integral y completa e involucra al personal de toda la organización, incluyendo muchas personas que no se consideran con responsabilidades contables o de control (e.g.: empleados que reportan tiempo empleado en proyectos o trabajos específicos). También involucra a aquellos que mantienen los registros contables, preparan y distribuyen políticas, o monitorean sistemas. Finalmente, involucra a los miembros de la junta directiva y de los comités de auditoría, cuya principal responsabilidad es supervisar el proceso de reporte de información financiera.

\section{Definir el Control Interno}

A fin de evaluar el control interno de una organización, se debe identificar primero los criterios sobre los cuales se hará la evaluación. Por lo tanto, es importante definir apropiadamente el control interno al comienzo del proceso de evaluación. En septiembre de 1992, COSO emitió un Informe que proporciona una definición de control interno y establece criterios que pueden ser usados para evaluar los controles internos de una organización (Luppi, 2010). El informe de COSO contiene la definición de control interno aceptada más ampliamente.

El informe de COSO define el control interno como un "proceso - efectuado por la junta directiva, la gerencia y otro personal de una entidad-diseñado para proporcio- nar seguridad razonable respecto al logro de objetivos en las tres categorías siguientes: eficacia y eficiencia de las operaciones, confiabilidad de la información financiera, y cumplimiento con leyes y regulaciones" (Committee of Sponsoring Organizations of the Treadway Commission, 2013, p. 8).

También identifica cinco componentes interrelacionados de un control interno eficaz que deben estar presentes (diseñados) y funcionando (efectivos), conjuntamente de manera integrada.

1. Entorno del control

2. Evaluación de riesgos

3. Actividades de control

4. Información y comunicación

\section{Monitoreo}

Además de los cinco componentes de control interno, COSO 2013 toma la esencia del COSO 1992 y formaliza 17 principios relevantes que ya estaban implícitos en un sistema con control interno efectivo (Ver Anexo I).

En este análisis, evaluaremos la eficacia de los controles internos y revisaremos cada uno de los componentes de control interno para evaluar y documentar la eficacia de dichos controles internos sobre la información financiera con base en las definiciones del informe de COSO.

Un lugar lógico para comenzar una evaluación general del control interno es la cúspide del control interno a nivel de 
empresa. Esta etapa incluye la revisión de aquellos elementos de los cinco compo- nentes del control interno que tienen un efecto dominante sobre la organización.

\section{Figura 1.}

\section{Estructura y objetivos del COSO 1992 - 2013}

Cubo $\cos 01992$

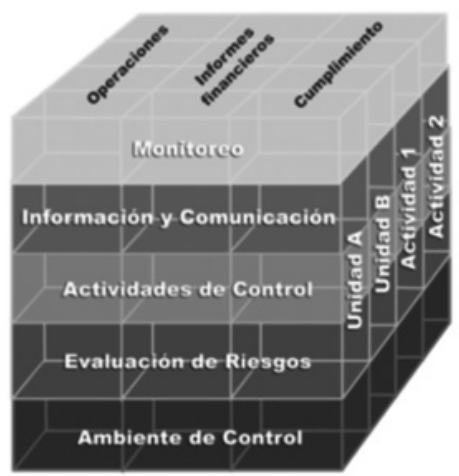

A continuación se listan los cinco componentes del control interno:

1. El entorno de control es lo que marca la pauta de una organización, o sea aquella base para influir en la conciencia de control de su personal Es el fundamento de los demás componentes del control interno, y provee disciplina y estructura.

2. La evaluación del riesgo es la identificación y el análisis de los riesgos relevantes que corre la empresa para el logro de sus objetivos, formando la base para determinar cómo se deben administrar los riesgos.

\section{Los sistemas de información y} comunicación soportan la base para identificar, capturar e intercambiar información en una forma y período de tiempo que permita al personal cumplir con sus responsabilidades.
Cubo COSO 2013

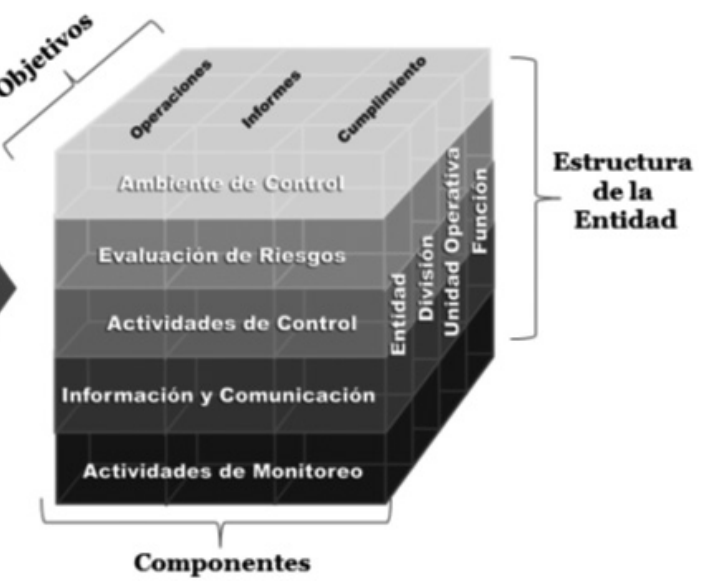

4. Las actividades de control son las políticas y los procedimientos que deben seguirse para tener certeza que las instrucciones de la gerencia se llevan a cabo.

5. Monitoreo es un proceso para verificar la calidad de desempeño del control interno a través del tiempo.

De manera general, describiremos cada uno de los componentes del control interno y el enfoque que puede tomar la Gerencia para la evaluación de cada uno de ellos en la empresa.

\section{Entorno de Control}

La Comisión Treadway afirmó que la pauta que marca la alta gerencia -o sea el entorno o cultura corporativa dentro de la cual funciona la información financiera ( financial reporting)- es el factor más importante 
que contribuye a la integridad del proceso de información financiera. En otras palabras, si la pauta marcada por la gerencia es relajada o poco estricta, un juego impresionante de reglas y procedimientos escritos logrará poco.

El entorno del control refleja la actitud general, el grado de conciencia y las acciones de la junta directiva, la gerencia, los dueños y otros concernientes a la importancia del control y el énfasis en el control sobre las políticas, procedimientos, métodos y estructura organizacional de la compañía.

El entorno de control incluye la actitud de la gerencia hacia el desarrollo de estimaciones contables y en la filosofía para reportar información financiera, es el contexto en que operan el sistema contable y los controles internos.

En su informe, Internal Control-Integrated Framework, COSO afirma que "el entorno de control tiene una influencia dominante sobre la manera en que se estructuran las actividades de negocio, como se establecen los objetivos y se evalúan los riesgos. También influye en las actividades de control, los sistemas de información y comunicación, y las actividades de monitoreo. Esto es cierto no solamente con respecto a su diseño, sino también a la forma en que funciona día a día" (Committee of Sponsoring Organizations of the Treadway Commission, 2013, p. 15).

El entorno del control es la atmósfera dentro de la cual existen los controles contables de una compañía y se preparan los estados financieros. Por lo tanto es esencial tener una comprensión del entorno de control para poder identificar los factores que tienen un efecto dominante sobre el riesgo de que existan errores en el procesamiento de transacciones y en los juicios que la gerencia hace cuando prepara estados financieros.

Sin embargo, un entorno de control satisfactorio no garantiza la eficacia de algún control específico, pero puede ser un factor positivo al evaluar el riesgo de errores. Un entorno de control eficaz también proporciona una base para esperar que los sistemas contables que están funcionando bien en un momento dado del año continúen funcionando bien el resto del año. De tal manera, el entorno de control es un ingrediente básico para tener controles internos eficaces.

Se debe tener en cuenta los siguientes factores durante la revisión del entorno de control:

\section{Integridad, valores éticos y el comporta- miento de los ejecutivos clave}

La integridad y los valores éticos son elementos esenciales del entorno de control, afectando el diseño, la administración y el monitoreo de los procesos clave. La integridad y el comportamiento ético son producto de las normas de la empresa sobre ética y comportamiento y de la manera de ser comunicadas, supervisadas y puestas en funcionamiento en la práctica. Incluyen las acciones que toma la gerencia para reducir o eliminar oportunidades de que el personal lleve a cabo acciones ilegales, deshonestas o contrarias a la ética. También incluyen las comunicaciones al personal de los valores 
de la empresa y sus normas de comportamiento a través de pronunciamientos de políticas y códigos de conducta, así como por ejemplos dados por sus ejecutivos.

\section{Conciencia de control de la gerencia y estilo operativo de la Gerencia}

La gerencia tiene la responsabilidad de dirigir y controlar las operaciones y establecer, comunicar y monitorear políticas y procedimientos. Cada aspecto del entorno del control se ve profundamente influenciado por las acciones y las decisiones (o, en algunos casos, por inacción e indecisión) de la gerencia. En un ambiente de control eficaz, la conciencia de control de la gerencia y su estilo de operar y coordinar, propicia una operación eficaz de los procesos y controles y un entorno en que la probabilidad de error se minimice. La conciencia de control se refiere a la importancia que la gerencia le da a los controles internos y, al entorno en que ellos funcionan. En gran parte este es un concepto intangible; es una actitud de la gerencia que, una vez comunicada, ayuda a lograr que un control adecuado permanezca en su lugar y reduzca la posibilidad de que controles específicos sean ignorados.

\section{Compromiso de ser competente}

El compromiso de ser competentes incluye la consideración de la gerencia de los niveles de competencia para puestos específicos y cómo estos niveles se traducen en requisitos de aptitudes y conocimientos. Entre otros factores que la gerencia debe considerar, está la naturaleza y el grado de juicio que se debe usar en una labor específica y el grado de supervisión que va a necesitar. El equipo a cargo del proyecto tiene que consi- derar si el personal parece ser competente para cumplir sus responsabilidades (por ejemplo, si el personal tiene el suficiente conocimiento y experiencia en el área de principios de contabilidad generalmente aceptados sobre los cuales la compañía va a reportar).

\section{Participación de la junta directiva y del comité de auditoría en el gobierno (gover- nance) y supervisión del negocio}

La junta directiva, a través de actividades propias y con el soporte de un comité de auditoría, es responsable de la supervisión de los procedimientos y políticas contables y de reporte de información financiera. Mientras que las actividades y responsabilidades específicas de los comités de auditoría varían y requieren modificaciones o adaptaciones conforme las circunstancias individuales, la junta directiva tiene una responsabilidad fiduciaria ante los accionistas y terceros por la presentación de reportes financieros confiables. Como resultado la junta directiva y el comité de auditoría deben estar preocupados de reportar información financiera a los accionistas y al público inversionista y deben monitorear las políticas contables de la compañía y los procesos de auditoría interna y auditoría independiente. $\mathrm{Al}$ determinar los efectos que tiene la junta directiva y/o el comité de auditoría sobre el entorno del control, el equipo a cargo del proyecto debe considerar la independencia de la junta directiva y/o el comité de auditoría con respecto a la gerencia, la experiencia y los conocimientos de sus miembros, el grado de participación y su escrutinio de las operaciones de la compañía, el grado en que surgen preguntas difíciles y se les da 
seguimiento con la gerencia y su interacción con los auditores internos y los auditores independientes.

\section{Estructura adecuada de la organización y asignación de autoridad y responsabi- lidades}

La estructura de organización de una empresa señala el marco general para la planeación, dirección y el control de las operaciones. Una estructura eficaz determina la asignación de responsabilidad, de tal manera que todo el personal tenga un claro concepto de quién es la persona a quien reportar y cuáles son sus responsabilidades.

\section{Políticas y prácticas de recursos humanos}

Estas políticas y procedimientos se refieren a la contratación, orientación, entrenamiento, evaluación, consejería, promoción y compensación del personal. La eficacia de las políticas y procedimientos, incluyendo los controles, depende de las personas que los ejecutan. Por lo tanto, la capacidad e integridad del personal de la compañía son elementos importantes de su entorno de control. La habilidad de una empresa para reclutar y contratar suficiente personal competente y responsable, depende a su vez de las políticas y prácticas de recursos humanos. Además, el nivel de competencia y de integridad del personal dedicado a procesos específicos es uno de los factores para evaluar la eficacia del control sobre los procesos.

Se deberá obtener un suficiente conocimiento del ambiente de control, para entender la actitud de la gerencia y del consejo de directores, conciencia y acciones relacionadas al ambiente de control, considerando tanto la sustancia de los controles y su efecto colectivo. Se debe concentrarse en la sustancia de controles diferentes en su forma, porque los controles pueden estar establecidos pero no están en acción. Por ejemplo, la gerencia puede establecer un código formal de conducta, pero actuar de una manera que perdone las violaciones de tal código.

Cuando se obtenga un entendimiento del ambiente de control, se debe considerar el efecto colectivo del mismo, sobre su resistencia y debilidad en varios factores de control ambiental. La resistencia y debilidad de la gerencia, pueden tener un efecto persuasivo sobre el control interno. Por ejemplo, el control de un gerente - dueño, puede mitigar una falta de segregación de deberes en una pequeña compañía de negocios, o una activa e independiente junta de directores, puede influenciar la filosofía y estilo de operación de una experimentada gerencia, a lo largo de sus actividades. Sin embargo, las políticas y prácticas de los recursos humanos, dirigidos a través de la competente contratación del personal financiero y contable, no puede aminorar una fuerte predisposición de la alta gerencia para subestimar las utilidades.

En el Anexo II adjunto, se ha detallado un ejemplo, a manera de encuesta, de cómo podría la gerencia evaluar el control interno a nivel de empresa, en el componente denominado "Entorno de control", Este ejemplo no abarca todo, y no todos los puntos listados serán aplicables a todas las compañías. Factores internos y externos únicos para una empresa en 
particular pueden dar como resultado que las compañías desarrollen mecanismos de control distintos, y esos factores pueden dar lugar a considerar puntos adicionales. Este ejemplo sería una referencia que una Gerencia puede tomar para evaluar el Control Interno a un alto nivel y poder tener el punto de partida para su evaluación en toda la organización.

\section{Evaluación de Riesgo}

Todas las empresas, independientemente de su tamaño, estructura, naturaleza o tipo de industria, encuentran riesgos en todos los niveles de su organización. Los riesgos afectan la habilidad que tiene una empresa para sobrevivir y para competir exitosamente dentro de su industria; para mantener su fortaleza financiera, su imagen pública positiva y la calidad general de sus productos o servicios y su personal. No hay manera práctica de reducir su riesgo a “cero". De hecho, la decisión misma de establecer un negocio, crea un riesgo. La gerencia debe decidir el nivel de riesgo que prudentemente puede aceptar y tratar de permanecer dentro de ese nivel.

El proceso de identificación, análisis y administración de riesgos es un componente crítico de cualquier sistema de control interno eficaz. También debe reconocerse que siempre está presente el cambio y es fundamental para un proceso eficaz de evaluación de riesgo tomar las acciones necesarias para responder a tales cambios.

Para comprender el proceso de evaluación de riesgo a nivel de empresa, se debe considerar factores tales como:
- Si se han establecido y comunicado los objetivos a nivel de empresa, incluyendo la manera como están soportados por planes estratégicos y complementados a nivel de proceso o de aplicación

- Si se ha establecido un proceso de evaluación de riesgos que incluya una estimación de la importancia de los riesgos, evaluación de las probabilidades de que ocurran, y determinación de las acciones necesarias

- Si se han establecido mecanismos para anticipar, identificar y reaccionar a situaciones que puedan tener un efecto dramáticamente extenso en la empresa. (Por ejemplo, un comité gerencial de administración de activos/pasivos en una institución financiera, o un grupo de riesgos de comercialización de commodities en una empresa manufacturera).

- Si existen mecanismos para anticipar, identificar y reaccionar a eventos rutinarios o a actividades que afecten el logro de los objetivos de la entidad o a nivel de proceso/aplicación.

- Si el departamento de contabilidad ha establecido procesos para identificar cambios significativos en los principios de contabilidad generalmente aceptados promulgados por las autoridades pertinentes.

- Si los canales de comunicación están facultados para notificar al departamento de contabilidad los cambios en las prácticas de negocios de la empresa 
que pueden afectar el método o el proceso de registrar transacciones.

- Si el departamento de contabilidad tiene procesos para identificar cambios importantes en el entorno operativo, incluyendo cambios regulativos.

\section{Sistemas de Información y Comunicación}

Información y comunicación es el proceso de capturar e intercambiar información que se necesita para ejecutar, administrar y controlar las operaciones de la empresa. La calidad del sistema de comunicación e información de la compañía afecta la habilidad de la gerencia para tomar las decisiones acertadas para controlar las actividades de la compañía y preparar reportes financieros confiables.

Información y comunicación abarcan la captura y la emisión de información al personal adecuado para que éste pueda cumplir con sus responsabilidades, incluyendo una comprensión de las funciones y responsabilidades individuales que atañen al control interno sobre reportes de información financiera.

Para entender la información y comunicación a nivel de empresa, se debe considerar factores tales como:

\section{Información}

- Si el sistema de información provee a la gerencia los informes necesarios sobre el desempeño de la empresa en relación con los objetivos establecidos, incluyendo información relevante tanto externa como interna.
- Si la información se provee a las personas adecuadas con suficiente detalle y anticipación para que puedan desempeñar sus responsabilidades eficientemente y con eficacia.

- Hasta qué grado los sistemas de información son desarrollados o modificados con base en un plan estratégico que está interrelacionado con el sistema general de información de la empresa, que permita el logro de los objetivos a nivel de empresa y de proceso/aplicación.

- Si la gerencia de la empresa asigna los recursos humanos y financieros adecuados para desarrollar los sistemas de información que sean necesarios.

- Cómo asegura y monitorea la gerencia la participación de usuarios en el desarrollo (incluyendo modificaciones) y pruebas de programas.

- Si se ha establecido un plan de recuperación en caso de desastre para todos los centros principales de datos.

\section{Comunicación}

- Si la gerencia comunica de manera eficaz las funciones y responsabilidades de control del personal.

- Si se han establecido canales de comunicación para las personas que tienen que reportar hechos sospechosos

- La idoneidad de la comunicación a través de la empresa para facilitar el 
desempeño de obligaciones por parte del personal.

- Si la gerencia toma oportuna y apropiada acción de seguimiento en relación con las comunicaciones de clientes, proveedores, mediadores y otras partes externas.

- Si la empresa está sujeta a requisitos de monitoreo y cumplimiento impuestos por organismos reguladores.

- El alcance de notificación a terceros fuera de la empresa (tales como clientes y proveedores) sobre las políticas y normas de ética de la empresa.

\section{Actividades de Control}

Las actividades de control son políticas y procedimientos que ayudan a asegurar que las instrucciones de la gerencia sean cumplidas. Ayudan a asegurar que se toman las acciones necesarias para tratar los riesgos en el logro de los objetivos de la empresa. Las actividades de control, automatizadas o manuales, tienen varios objetivos y se aplican a varios niveles organizacionales y funcionales.

Para comprender las actividades de control a nivel de empresa, se debe de tomar en cuenta factores tales como:

- Si existen las políticas y los procedimientos que se requieren respecto a cada actividad de la empresa.

- Si los controles se aplican con la extensión que requiere cada política.
- Si la gerencia tiene objetivos claros en términos de presupuesto, utilidades, otras metas financieras y de operación y estos objetivos son expresados con claridad y comunicados a toda la organización, y son monitoreados continuamente.

- Si hay sistemas establecidos de información y de planeación para identificar variaciones en el desempeño planeado y comunicar tales variaciones a nivel apropiado de gerencia.

- Grado en que las funciones están segregadas entre diferentes personas de tal manera que se reduce el riesgo de fraude o de otros actos impropios.

- Grado en que las funciones están divididas lógicamente por medio de aplicaciones de tecnología de información (IT).

- Si se hacen comparaciones periódicas de los importes registrados en el sistema contable con los activos físicos.

- Si existen salvaguardias adecuadas para evitar el acceso no autorizado o la destrucción de documentos, registros y activos.

- Si se han establecido políticas para controlar el acceso a archivos de datos y programas.

- Si se usa algún software de seguridad de acceso, de sistema operativo, y/o de aplicaciones para controlar el acceso a datos y programas. 
- Si existe una función establecida de seguridad de información con la responsabilidad de monitorear el cumplimiento con las políticas y procedimientos de seguridad de información.

\section{Monitoreo}

Una importante responsabilidad de la gerencia es el establecimiento y mantenimiento del control interno. La gerencia monitorea los controles para cerciorarse de que funcionen conforme a lo diseñado, y si se han modificado para adaptarlos a condiciones cambiantes. Monitoreo es un proceso de evaluación para determinar la calidad del control interno a través del tiempo, considerando si los controles están operando para lo que fueron diseñados y asegurando que son modificados apropiadamente por condiciones cambiantes. Esto implica evaluar el diseño y la operación de los controles con regularidad, tomando las acciones correctivas necesarias. Este proceso se logra mediante actividades sobre la marcha y evaluaciones separadas, o combinaciones de ambas.

Para comprender el proceso de monitoreo a nivel de empresa, se debe tener presente factores tales como:

- Si se llevan a cabo evaluaciones periódicas del control interno.

- Grado en que el personal, en el desarrollo de sus funciones regulares, obtiene evidencia de que el sistema de control interno continúa funcionando.

- Grado en que las comunicaciones de partes externas corroboran la informa- ción generada internamente o indican problemas.

- Si la gerencia sigue las recomendaciones que le hacen los auditores internos y los auditores independientes.

- Enfoque de la gerencia para corregir oportunamente las condiciones informales conocidas.

- Enfoque de la gerencia para manejar los reportes y recomendaciones provenientes de autoridades reguladoras.

Existencia de una función de la auditoría interna que la gerencia usa para ayudarse en el monitoreo, la cual incluye factores tales como:

- Independencia (autoridad y relaciones de reporte).

- Líneas de reporte (se reporta directamente a la junta directiva y/o al comité de auditoría, o se tiene acceso ilimitado a la junta directiva y/o al comité de auditoría).

- Idoneidad en la asignación de personal, entrenamiento y existencia de destrezas especializadas de acuerdo con el entorno (e.g.: uso de auditores de sistemas de información experimentados, adiestrados en entornos complejos y altamente automatizados).

- Cumplimiento con las normas profesionales aplicables.

- Alcance de actividades (un balance entre auditorias financieras y operacionales, 
cobertura y rotación de operaciones descentralizadas).

- Idoneidad de la planeación, evaluación de riesgos y documentación del trabajo ejecutado y las conclusiones alcanzadas.

- Inexistencia de responsabilidades operativas.

\section{Conclusiones}

Como hemos podido revisar, este documento podría ayudar a la Gerencia en proporcionarle una metodología para transformar la estructura conceptual de COSO en una evaluación detallada y significativa de los controles internos sobre su información financiera. Es importante entonces definir que hoy en día más que nunca es indispensable conocer y determinar el adecuado control interno que debe de tener una empresa para poder identificar si está sujeta a algún riesgo de negocio o un riesgo generado por sus propias operaciones (Ernst \& Young, 2003).

La evaluación general del control interno a nivel de empresa finalmente lleva a dos preguntas:

- ¿La gerencia ha creado un entorno de control en el que se motiva al personal a cumplir con controles en lugar de ignorarlos o burlarlos?
- ¿La empresa ha implantado los mecanismos de control necesarios para observar el sistema y corregir las faltas de cumplimiento? ¿Los mecanismos están funcionando eficazmente?

Estas preguntas pueden ser contestadas si la empresa ha diseñado un ambiente de control interno basado en el enfoque COSO descrito anteriormente.

\section{Referencias}

Committee of Sponsoring Organizations of the Treadway Commission (1992). "Internal Control Integrated Framework”. USA: COSO.

Committee of Sponsoring Organizations of the Treadway Commission (2013). “Executive Resume”. USA: COSO.

Méndez, H. (2011). La auditoría: Conceptos, clases y evolución. "Auditoría”, 15, 9-21.

Securities and Exchange Commission (2002). "Sarbanes - Oxley Act of 2002". Public Law 107 - 204.

Ernst \& Young (2003). Evaluación del control interno: Consideraciones para evaluar el control interno a nivel empresa. Arequipa.

Luppi, H. (2010). "Control interno hoy. El informe COSO”. Madrid: McGraw-Hill.

Recibido: 29-10-2015

Aceptado: 02-12-2015 


\section{Anexo I}

Los 17 principios fundamentales de $\operatorname{COSO} 2013$ (asociados a los 5 componentes de control interno)

Ambiente de control

Principio 1: Demostrar compromiso con la integridad y valores éticos.

Principio 2: El consejo de administración ejerce su responsabilidad de supervisión del control interno.

Principio 3: Establecimiento de estructuras, asignación de autoridades y responsabilidades.

Principio 4: Demuestra su compromiso de reclutar, capacitar y retener personas competentes.

Principio 5: Retiene a personal de confianza y comprometido con las responsabilidades de control interno.

Evaluación de riesgos

Principio 6: Se especifican objetivos claros para identificar y evaluar riesgos para el logro de los objetivos.

Principio 7: Identificación y análisis de riesgos para determinar cómo se deben mitigar.

Principio 8: Considerar la posibilidad del fraude en la evaluación de riesgos.

Principio 9: Identificar y evaluar cambios que podrían afectar significativamente el sistema de control interno.

Actividades de control

Principio 10: Selección y desarrollo de actividades de control que contribuyan a mitigar los riesgos a niveles aceptables.

Principio 11: La organización selecciona y desarrolla actividades de controles generales de tecnología para apoyar el logro de los objetivos.

Principio 12: La organización implementa las actividades de control a través de políticas y procedimientos.

Información y Comunicación

Principio 13: Se genera y utiliza información de calidad para apoyar el funcionamiento del control interno.

Principio 14: Se comunica internamente los objetivos y las responsabilidades de control interno.

Principio 15: Se comunica externamente los asuntos que afectan el funcionamiento de los controles internos.

Actividades de monitoreo

Principio 16: Se lleva a cabo evaluaciones sobre la marcha y por separado para determinar si los componentes del control interno están presentes y funcionando.

Principio 17: Se evalúa y comunica oportunamente las deficiencias del control interno a los responsables de tomar acciones correctivas, incluyendo la alta administración y el consejo de administración. 


\section{Anexo II}

\section{Entorno de Control (enfoque sugerido)}

El entorno de control refleja la pauta fijada por la alta gerencia y la actitud general, la conciencia y las acciones de la junta directiva, la gerencia, los dueños y otros, con respecto a la importancia del control interno y el énfasis puesto sobre el control en las políticas, procedimientos, métodos y estructura organizacional de la compañía. Esto es el fundamento para todos los otros componentes del control interno, que proveen disciplina y estructura.

\begin{tabular}{|c|c|c|}
\hline Puntos a considerar & & Respuestas/Comentarios \\
\hline \multicolumn{3}{|l|}{ Integridad, valores éticos, y comportamiento de los ejecutivos clave } \\
\hline $\begin{array}{l}\text { - Muestra la junta directiva interés por la integridad y los valores } \\
\text { éticos? Hay un código de conducta y/o una política de ética, y } \\
\text { estos han sido comunicados adecuadamente? }\end{array}$ & $\square$ Sí & $\square$ No Comentarios: \\
\hline $\begin{array}{l}\text { - Se ha comunicado eficazmente el compromiso de la gerencia } \\
\text { a la integridad y el comportamiento ético a toda la compañía, } \\
\text { tanto en palabras como en hechos? La gerencia lidera dando el } \\
\text { ejemplo? }\end{array}$ & $\square$ Sí & $\square$ No Comentarios: \\
\hline $\begin{array}{l}\text { - Se le pide al personal de la alta gerencia que ha sido contratado } \\
\text { fuera de la compañía que se familiarice con la importancia de } \\
\text { altos valores éticos y controles? }\end{array}$ & $\square$ Sí & $\square$ No Comentarios: \\
\hline $\begin{array}{l}\text { - Trata la gerencia de eliminar o reducir los incentivos o tenta- } \\
\text { ciones que pueden propiciar que el personal se involucre en } \\
\text { actos fraudulentos, ilegales o no éticos? }\end{array}$ & $\square$ Sí & $\square$ No Comentarios: \\
\hline $\begin{array}{l}\text { - Otorga la gerencia recompensas, tales como bonos o acciones } \\
\text { de la compañía, fomentando un tono ético apropiado (p. ej., } \\
\text { estas no se otorgan a quienes cumplen objetivos, sino, en el } \\
\text { proceso, evaden las políticas, procedimientos o controles esta- } \\
\text { blecidos)? }\end{array}$ & $\square$ Sí & $\square$ No Comentarios: \\
\hline \multicolumn{3}{|l|}{ Conciencia de control de la gerencia y estilo operativo } \\
\hline $\begin{array}{l}\text { - Es apropiada la estructura de la gerencia (p. ej., no es domina- } \\
\text { da por uno o unos pocos individuos) y existe una supervisión } \\
\text { eficaz por parte de la junta directiva y/o el comité de auditoría? }\end{array}$ & $\square$ Sí & $\square$ No Comentarios: \\
\hline $\begin{array}{l}\text { - Existe un mecanismo establecido para educar y comunicar re- } \\
\text { gularmente a la gerencia y a los empleados la importancia de } \\
\text { los controles internos, y elevar el nivel de entendimiento de los } \\
\text { controles? }\end{array}$ & $\square$ Sí & $\square$ No Comentarios: \\
\hline
\end{tabular}




\begin{tabular}{|c|c|c|}
\hline Puntos a considerar & & Respuestas/Comentarios \\
\hline $\begin{array}{l}\text { - Presta la gerencia la apropiada atención al control interno, in- } \\
\text { cluyendo los efectos del procesamiento de sistemas de infor- } \\
\text { mación? }\end{array}$ & $\square$ Sí & $\square$ No Comentarios: \\
\hline $\begin{array}{l}\text { - Corrige la gerencia oportunamente las deficiencias identifica- } \\
\text { das en el control interno? }\end{array}$ & $\square$ Sí & $\square$ No Comentarios: \\
\hline $\begin{array}{l}\text { - Están equilibrados los incentivos a la gerencia (p. ej., la parte } \\
\text { de la compensación de la gerencia derivada de bonos, opcio- } \\
\text { nes de compra de acciones, u otros incenti vos no promueve un } \\
\text { excesivo nivel de interés en mantener o aumentar el precio de } \\
\text { las acciones o las ganancias de la empresa)? }\end{array}$ & $\square$ Sí & $\square$ No Comentarios: \\
\hline \multicolumn{3}{|l|}{ Compromiso de la gerencia a ser competente } \\
\hline $\begin{array}{l}\text { - Parece el personal tener la capacidad y el entrenamiento nece- } \\
\text { sarios para su nivel de responsabilidad asignado o la naturale- } \\
\text { za y complejidad del negocio? }\end{array}$ & $\square$ Sí & $\square$ No Comentarios: \\
\hline $\begin{array}{l}\text { - Posee la gerencia una amplia experiencia funcional (la geren- } \\
\text { cia viene de varias áreas funcionales en vez de sólo unas pocas, } \\
\text { tales como producción y ventas)? }\end{array}$ & $\square$ Sí & $\square$ No Comentarios: \\
\hline $\begin{array}{l}\text { - Es apropiado el personal departamental, (particularmente } \\
\text { con respecto al conocimiento y experiencia de la gerencia y los } \\
\text { niveles supervisores dentro de las áreas de contabilidad, siste- } \\
\text { mas de información y reporte de información financiera)? }\end{array}$ & $\square$ Sí & $\square$ No Comentarios: \\
\hline $\begin{array}{l}\text { - Muestra la gerencia una voluntad de consultar con los audi- } \\
\text { tores y tratar asuntos significativos que se relacionan con el } \\
\text { control interno y asuntos de contabilidad? }\end{array}$ & $\square$ Sí & $\square$ No Comentarios: \\
\hline \multicolumn{3}{|c|}{$\begin{array}{l}\text { Participación de la junta directiva y/o el comité de auditoría en el gobierno (govemance) y la vi } \\
\text { gilancia }\end{array}$} \\
\hline $\begin{array}{l}\text { - Es apropiada la estructura de la junta directiva, incluyendo el } \\
\text { número de directores, sus antecedentes y experiencia, dada la } \\
\text { naturaleza de la compañía? La independencia de los miem- } \\
\text { bros externos de la junta directiva ha sido revisada adecuada- } \\
\text { mente, incluyendo afiliaciones, relaciones y transacciones con } \\
\text { la compañía? }\end{array}$ & $\square$ Sí & $\square$ No Comentarios: \\
\hline $\begin{array}{l}\text { - Son independientes de la gerencia, la junta directiva y el comi- } \\
\text { té de auditoría, tanto así que con frecuencia indagan y plan- } \\
\text { tean preguntas según sea necesario? }\end{array}$ & $\square$ Sí & $\square$ No Comentarios: \\
\hline $\begin{array}{l}\text { - Consideran adecuadamente la junta directiva y/o el comité de } \\
\text { auditoría la importancia del entendimiento de los procesos } \\
\text { que la gerencia emplea para monitorear los riesgos de negocios } \\
\text { que afectan a la organización? }\end{array}$ & $\square$ Sí & $\square$ No Comentarios: \\
\hline
\end{tabular}




\begin{tabular}{|c|c|c|}
\hline Puntos a considerar & & Respuestas/Comentarios \\
\hline $\begin{array}{l}\text { - Incluye el comité de auditoría al menos a un "experto financie- } \\
\text { ro" (financial expert)? }\end{array}$ & $\square$ Sí & $\square$ No Comentarios: \\
\hline $\begin{array}{l}\text { - Tiene el comité de auditoría un documento que defina sus } \\
\text { deberes y responsabilidades? Tiene el comité de auditoría los } \\
\text { recursos adecuados y la autoridad para ejercer sus responsabi- } \\
\text { lidades? }\end{array}$ & $\square$ Sí & $\square$ No Comentarios: \\
\hline \multicolumn{3}{|c|}{ Estructura organizacional y asignación de autoridad y responsabilidades } \\
\hline $\begin{array}{l}\text { - Es la estructura organizacional adecuada para el tamaño, acti- } \\
\text { vidades operacionales, y ubicación de la compañía? }\end{array}$ & $\square$ Sí & $\square$ No Comentarios: \\
\hline $\begin{array}{l}\text { - Es apropiada la estructura organizacional general (es decir, no } \\
\text { demasiado compleja, ni abarca numerosas empresas jurídicas } \\
\text { o poco usuales, líneas administrativas de autoridad, o conve- } \\
\text { nios contractuales sin propósito aparente de negocios)? }\end{array}$ & $\square$ Sí & $\square$ No Comentarios: \\
\hline $\begin{array}{l}\text { - Existe una estructura apropiada para asignar la propiedad de } \\
\text { la información, incluso quiénes están autorizados para iniciar } \\
\text { y/o modificar transacciones? Se asigna la propiedad para cada } \\
\text { aplicación y base de datos dentro de la infraestructura de IT? }\end{array}$ & $\square$ Sí & $\square$ No Comentarios: \\
\hline $\begin{array}{l}\text { - Hay políticas y procedimientos apropiados para la autoriza- } \\
\text { ción y aprobación de transacciones al nivel adecuado? }\end{array}$ & $\square$ Sí & $\square$ No Comentarios: \\
\hline $\begin{array}{l}\text { - Es clara la asignación de responsabilidades, incluyendo res- } \\
\text { ponsabilidades del procesamiento de sistemas de información } \\
\text { y desarrollo de programas? }\end{array}$ & $\square$ Sí & $\square$ No Comentarios: \\
\hline $\begin{array}{l}\text { - Hay una apropiada segregación de actividades incompatibles } \\
\text { (es decir, la separación entre la contabilización y el acceso a } \\
\text { activos)? }\end{array}$ & $\square$ Sí & $\square$ No Comentarios: \\
\hline \multicolumn{3}{|l|}{ Políticas y prácticas de recursos humanos } \\
\hline $\begin{array}{l}\text { - Existen normas y procedimientos para la contratación, adies- } \\
\text { tramiento, motivación, evaluación, promoción, remunera- } \\
\text { ción, traslados y terminación de personal que sean aplicables } \\
\text { a todas las áreas funcionales (p.ej., contabilidad, mercadeo, } \\
\text { sistemas de información)? }\end{array}$ & $\square$ Sí & $\square$ No Comentarios: \\
\hline $\begin{array}{l}\text { - Existen procedimientos de investigación para la selección de } \\
\text { solicitantes de empleo, particularmente para personal con ac- } \\
\text { ceso a activos susceptibles a sustracción? }\end{array}$ & $\square$ Sí & $\square$ No Comentarios: \\
\hline $\begin{array}{l}\text { - Son claras las políticas y procedimientos y se emiten, actuali- } \\
\text { zan y modifican oportunamente? Se comunican eficazmente } \\
\text { al personal en localidades descentralizadas y/o extranjeras? }\end{array}$ & $\square$ Sí & $\square$ No Comentarios: \\
\hline $\begin{array}{l}\text { - El desempeño del trabajo es evaluado y revisado periódica- } \\
\text { mente con cada empleado? }\end{array}$ & $\square$ Sí & $\square$ No Comentarios: \\
\hline
\end{tabular}

